\title{
Evaluation of drag models for CFD simulation of fluidized bed biomass gasification
}

\author{
Kjell-Arne Solli, Cornelius Agu \\ Department of Process, Energy and Environmental Technology, University College of Southeast Norway, Norway \\ kjell-arne.sollidusn.no
}

\begin{abstract}
Gasification of biomass into suitable feedstock has become a feasible alternative technology for reducing the use of energy feedstock from fossil sources. Usually, fluidized bed technology is used in the biomass gasification reactor.

Optimization of a fluidized bed reactor needs to take into account the bed behavior in the presence of both biomass and bed material, as well as chemical conversion of particles and volatiles, among other process parameters. CFD simulation of the process is a valuable tool to go about the optimization. However, simulation result validation is limited by the accuracy of input parameters such as those characterizing several drag models given in the literature. This study is focusing on the drag model parameters.

The simulation is aimed at validating some of the commonly used models for drag forces against the bed material(s) used in the fluidized bed gasification reactor. Drag models included in this study are those given by Syamlal and O'Brien, Gidaspow, and BVK. The MFiX CFD-software (version 2016.1) from The National Energy Technology Laboratory (NETL) is used. The Two-Fluid Model (TFM) are applied for comparison of the results. The key factors for validation of the drag models are based on the superficial gas velocity at the minimum fluidization condition and the degree of bed expansion.
\end{abstract}

The simulation results show that the minimum fluidization velocity could be predicted using the Gidaspow and BVK drag models by adjusting the particle diameter used in the simulation. For the Syamlal \& O'Brien drag model, two parameters are fitted to predict the minimum fluidization velocity. The bubbling bed behavior is not captured using the Syamlal \& O'Brien drag model while Gidaspow and BVK drag models fairly captures this phenomenon. The bed expansion from the simulation is higher than that observed in the experiment, and the deviation is even higher with the Syamlal \& O'Brien drag model.

Keywords: CFD, fluidized bed, drag model, TFM

\section{Introduction}

This studt is part of ongoing research project at Porsgrunn campus of University College of Southeast
Norway, aiming at improving on the processes utilizing alternative fuels from biomaterials.

\subsection{Background}

Gasification of biomass into suitable feedstock for energy production has become a feasible alternative technology for reducing the use of energy feedstock from fossil sources. Usually, fluidized bed technology is used in the biomass gasification reactor

Optimization of a fluidized bed for a biomass gasification process needs to take into account the fluidization behavior of a mixture of biomass and bed material, as well as chemical conversion of particles and volatiles, among other process parameters. CFD simulation of the process is a valuable tool to go about the optimization. However, simulation result validation is limited by the accuracy of input parameters such as those characterizing several drag models given in the literature. Due to limited space, this study is focusing on the drag model parameters.

The simulation setup is based on the physical dimensions used in a cold flow experiments $(1.5 \mathrm{~m}$ high, $8.4 \mathrm{~cm}$ diameter). This study supports simulation of a $20 \mathrm{~kW}$ fluidized bed gasification reactor located at University College of Southeast Norway.

\subsection{Aims}

The simulation is aimed at validating some of the commonly used models for drag forces against the bed material used in the fluidized bed gasification reactor. Drag models included in this study are those given by Syamlal and O'Brien (Syamlal \& O'Brien, 1988), Gidaspow (Ding \& Gidaspow, 1990), and Beetstra et al. (BVK model) (Beetstra et al., 2007).

\section{Methods}

The bed material has been characterized, and tested in cold bed setup. The results are compared with CFD simulations using different drag models. The key factors for validation of the drag models are based on the superficial gas velocity at the minimum fluidization condition and the degree of bed expansion. Distribution of void fraction and bubbles within the bed are also considered. 


\subsection{Cold bed experimental setup}

The experimental setup consists of a vertical cylindrical column of height $1.5 \mathrm{~m}$ and base diameter of $0.084 \mathrm{~m}$ as shown in Figure 1. The bottom of the column is fitted with a porous plate. The porous plate ensures even distribution of air within the bed. The rig is fitted with ten pressure sensors, measuring the fluid pressure in the column up to the height of about $1.0 \mathrm{~m}$. The pressure measurement $\mathrm{P} 2$ is placed $0.038 \mathrm{~m}$ above porous plate. Compressed air at ambient temperature is used as the fluidizing medium. Characterization of bed material and the experimental conditions are given in Table 1 and Table 2.

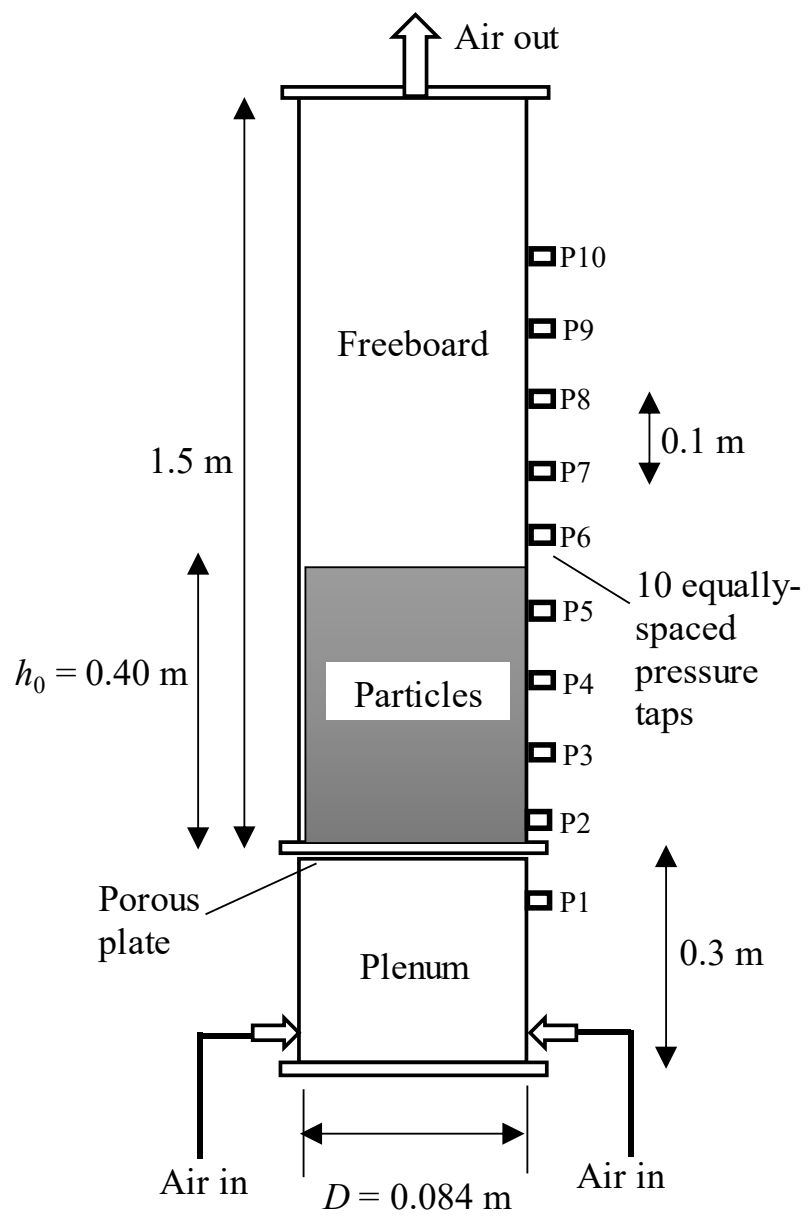

Figure 1. Physical dimensions of the fluidized bed column. Positions of pressure sensors P1 to P10 are indicated.

The experiments were conducted at increasing gas flow rate from $0.02 \mathrm{~m} / \mathrm{s}$ to $0.40 \mathrm{~m} / \mathrm{s}$. For each volumetric airflow rate, the pressure data were acquired over $60 \mathrm{~s}$. Two cases were demonstrated to compare the influence of gas distributor plate on the hydrodynamics of the bed. In one case, the porous plate is fitted while air is allowed into the bed across the plate. In the second case, the plate was removed for the same range of gas velocities. With porous plate removed, the bed material falls down into plenum, and extra bed material was added to compensate the dead zone below air inlet. With the porous plate in place, the pressure drops across the bed at two different positions were computed from $\frac{\Delta P}{\Delta L}=$ $(P 2-P 4) / L$ and $\frac{\Delta P}{\Delta L}=(P 4-P 6) / L$, where $L=$ $0.02 \mathrm{~m}$. With no porous plate, the pressure drops were obtained from $\frac{\Delta P}{\Delta L}=(P 1-P 3) / L$ and $\frac{\Delta P}{\Delta L}=(P 3-$ P5)/L.

Table 1. Characterization of bed material.

\begin{tabular}{|l|l|}
\hline \multicolumn{2}{|c|}{ Sand particles } \\
\hline Sauter particle diameter & $484 \mu \mathrm{m}$ \\
\hline Sphericity & 0.75 \\
\hline Particle density & $2650 \mathrm{~kg} / \mathrm{m}^{3}$ \\
\hline Bulk density & $1444 \mathrm{~kg} / \mathrm{m}^{3}$ \\
\hline Calculated solids void fraction & 0.545 \\
\hline
\end{tabular}

Table 2. Experimental conditions.

\begin{tabular}{|l|l|}
\hline Fluid & Compressed air \\
\hline Fluid temperature & Ambient \\
\hline Fluidizing air velocity & 0.02 to $0.40 \mathrm{~m} / \mathrm{s}$ \\
\hline Initial bed height $h_{0}$ & $0.40 \mathrm{~m}$ \\
\hline Outlet pressure & Atmospheric \\
\hline
\end{tabular}

\subsection{CFD Simulation software}

The CFD simulations are performed using the MFiX CFD-software (version 2016.1) from The National Energy Technology Laboratory (NETL) ${ }^{1}$. The theory used for simulations is outlined by Syamlal et al. (Syamlal et al., 1993) and a brief overview of MFiX equations is given by $\mathrm{Li}$ et al. (Li et al., 2010).

The interaction of solids and fluid has been simulated using the two-fluid-model (TFM), which is an EulerEuler fluid-particle multiphase transport model. For fluidized beds, the Eulerian formulation of the solid phase conservation equations is favorable due to the high solids loading occurring in such systems. The solid phase is treated as a continuous fluid although it actually consists of many individual particles. Thus, the tangential and normal forces are represented by a solids viscosity and the so-called solid pressure. Furthermore, a model for the drag force between the phases is required. One disadvantage of the Eulerian approach is the necessity to use a separate set of conservation equations for each size and density class of particles.

\footnotetext{
${ }^{1}$ https://mfix.netl.doe.gov/
} 


\subsection{Particle diameter in fluid dynamics}

Fluid-particles drag forces mostly characterize the fluidized beds. The drag forces act against the forces due to the weight of solid particles in the bed. At the minimum fluidization condition, these two opposite forces become equal. This indicates that the bed bulk density (product of material density and the solids volume fraction), is a key input parameter for the simulation. Since the fluid-particles drag forces depends on the particle size, particle size distribution and particle shape, these parameters play also key roles in the simulation inputs. Most models for calculating drag forces assume spherical and mono-sized particles, thus it is necessary to apply some corrections factors to account for differences in simulation model against the real situation when the non-spherical particles are used. In general, this can be achieved by replacing the nominal particle diameter with an equivalent diameter that results in the correct forces calculated.

The Sauter mean diameter, $D_{s d}$, is commonly used to characterize particles having the same volume/surface area ratio as a particle of interest. In its simplest form, it can be expressed as:

$$
D_{s d}=6 \frac{V_{p}}{A_{p}}
$$

where $V_{p}$ and $A_{p}$ are the volume and the surface area of the particle, respectively. Several measurements are usually carried out to obtain the average value.

Another property characterizing particles is the sphericity, which measures the extent a single particle resembles a perfect spherical particle. As defined by Wadell (Wadell, 1935), it is the ratio of the surface area of a sphere (with the same volume as the given particle) to the surface area of the particle:

$$
\varphi=\frac{\pi^{1 / 3}\left(6 V_{p}\right)^{2 / 3}}{A_{p}}
$$

Another definition is given by Krumbein (Krumbein, 1941) as:

$$
\varphi=\sqrt[3]{\frac{V_{p}}{V_{c}}} \approx \frac{D_{p}}{D_{c}}
$$

where $V_{c}$ and $D_{c}$ are the volume and the diameter of a circumscribed sphere around the particle, respectively, and $D_{p}$ is the nominal diameter of the particle. Nominal diameter of particle can be considered as the average diameter of sieve used and the circumscribed sphere diameter can be obtained from optical measurements.

The effect of broad or narrow particle size distribution (PSD) on the decision made on which equivalent diameter results in the correct forces, is not well described in literature. Furthermore, the outcome of a measurement of PSD depends on the method used (optical measurements, sieving, laser diffraction etc). For this study, the equivalent diameter, $D_{e q}$ used in the simulation is obtained by trials based on computation of minimum fluidization velocity and comparing the results with the experimental data. The trial simulation is initiated with the effective particle diameter $\varphi D_{p}$, which corresponds to the equivalent diameter where $a=1$ as given in Equation (4).

$$
D_{e q}=\varphi^{a} \times D_{p}
$$

\subsection{Drag models}

The drag models considered in this study are those given by Syamlal and O'Brien (Syamlal \& O'Brien, 1988), Gidaspow (Ding \& Gidaspow, 1990), and Beetstra et al. (BVK model) (Beetstra et al., 2007). The implementation in MFiX software requires no further input for the Gidaspow and BVK models. The MFiX implementation of the Syamlal and O'Brien drag model requires two parameters to fit the experimental data or calculated value for minimum fluidization velocity. A calculation sheet for this parameter fitting is supplied at the NETL web site (Syamlal). The parameters used for this work are given in Table 3.

Table 3. Syamlal and O'Brien drag model parameters

\begin{tabular}{|l|l|l|}
\hline $\begin{array}{l}\text { Particle } \\
\text { diameter }\end{array}$ & Parameter cl & Parameter d1 \\
\hline $484 \mu \mathrm{m}$ & 0.299 & 8.70669 \\
\hline $363 \mu \mathrm{m}$ & 0.428 & 6.50441 \\
\hline
\end{tabular}

\begin{tabular}{|c|c|}
\hline \multicolumn{2}{|c|}{ Materials: } \\
\hline \multicolumn{2}{|c|}{ Fluid: Air, density $=0.001178 \mathrm{~g} / \mathrm{cm}^{3}$} \\
\hline \multicolumn{2}{|c|}{ Particles: See Table 1} \\
\hline \multicolumn{2}{|c|}{ TFM parameters: } \\
\hline $\begin{array}{l}\text { Coefficient of Restitution } \\
\text { Particle-Particle } \\
\text { Particle-Wall } \\
\text { Specularity } \\
\end{array}$ & $\begin{array}{l}0.95 \\
1.0 \\
0.6 \\
\end{array}$ \\
\hline $\begin{array}{l}\text { Friction Coefficient } \\
\text { Friction Angle }\end{array}$ & $\begin{array}{l}0.5 \\
60.0 \\
\end{array}$ \\
\hline $\begin{array}{l}\text { Minimum Solid Fraction } \\
\text { Packed Void Fraction }\end{array}$ & $\begin{array}{l}0.5 \\
0.455 \\
\end{array}$ \\
\hline \multicolumn{2}{|c|}{ Simulation Grid $=2$ D Cartesian: } \\
\hline $\mathrm{X}$ Length $=8.4 \mathrm{~cm}$ & 10 X-Cells á $0.84 \mathrm{~cm}$ \\
\hline Y Length $=150 \mathrm{~cm}$ & 100 Y-Cells á $1.5 \mathrm{~cm}$ \\
\hline \multicolumn{2}{|c|}{ Boundary Conditions: } \\
\hline \multicolumn{2}{|c|}{$\begin{array}{l}\text { Mass Inflow bottom at } 300 \mathrm{~K} \\
\text { Gas velocities varied }\end{array}$} \\
\hline Pressure outflow top at 10 & $5 \mathrm{Ba}$ \\
\hline
\end{tabular}

\subsection{CFD Simulation Parameters}

The simulation parameters are listed in Table 4.

Table 4. CFD simulation parameters 


\section{Results and discussion}

The minimum gas velocity for fluidization is obtained from the variation of the calculated bed pressure drops with gas velocities. Typically, the pressure drop over the bed is linearly increasing with gas velocity for gas velocities below the minimum fluidization velocity, and invariant of gas velocities above the minimum fluidization velocity. Bubbles rising in the fluidized bed results in fluctuations of the pressure drops. The reported data for pressure drops are timed-average values taken over the last $1.5 \mathrm{~min}$ of the $4 \mathrm{~min}$ simulation time. The minimum fluidization velocity is obtained at the point of intersection between the lines fitting the data within the fixed and fluidized states.

The rate of bubble rise and eruption from the bed is visible through the increase in pressure fluctuations, and based on this the bubble frequency is calculated for different velocities. Similarly, the time profile of void fraction at a fixed height also gives information about bubble frequency and size.

In the simulation, the total bed height at a given gas velocity is deduced from the pressure profile along the vertical positions in the column. The center of the lowest computational cell where there is no further increase in pressure is used as the top of bed; see Figure 2 for an example. This method results in a small systematic error due to a limited cell resolution used for the calculation. The error is cancelled out when calculating the bed height increase.

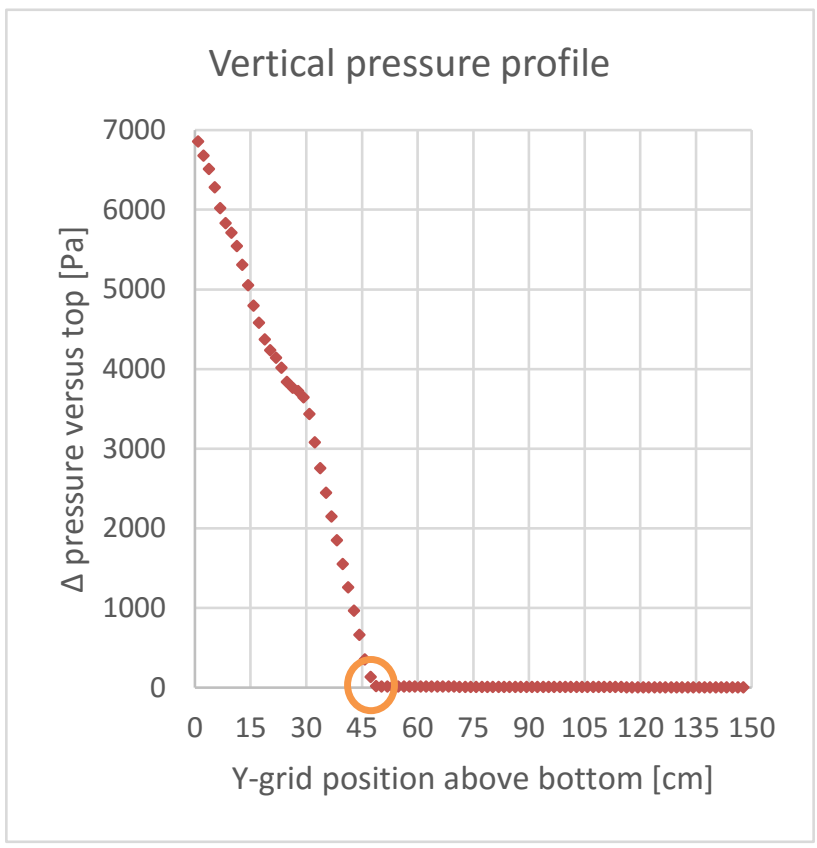

Figure 2 Vertical pressure profile taken for X-grid $=4.2 \mathrm{~cm}$ (middle). The top of bed is marked with the circle. This curve shows results from Gidaspow drag model simulation for $0.21 \mathrm{~m} / \mathrm{s}$ superficial gas velocity (319 $\mu \mathrm{m}$ particles); see Figure 14 . The pressure profile also shows an evidence of bubble flow at height $=28 \mathrm{~cm}$.

\subsection{Cold bed results}

The experimental bed pressure drops at different gas velocities are shown in Figure 3. Results from similar runs with the porous distributor plate removed are also shown. From these results, the minimum fluidization velocity of the sand particles is determined as $0.156 \mathrm{~m} / \mathrm{s}$ for the case with gas distributor. For the case where there is no gas distributor, the figure shows that a slightly higher minimum fluidization velocity could be obtained. The results also show that the bed pressure drop is lower without a gas distributor for the same superficial air velocity. There are also variations in the maximum pressure drops in both cases compared with the static pressure due to weight of the bed.

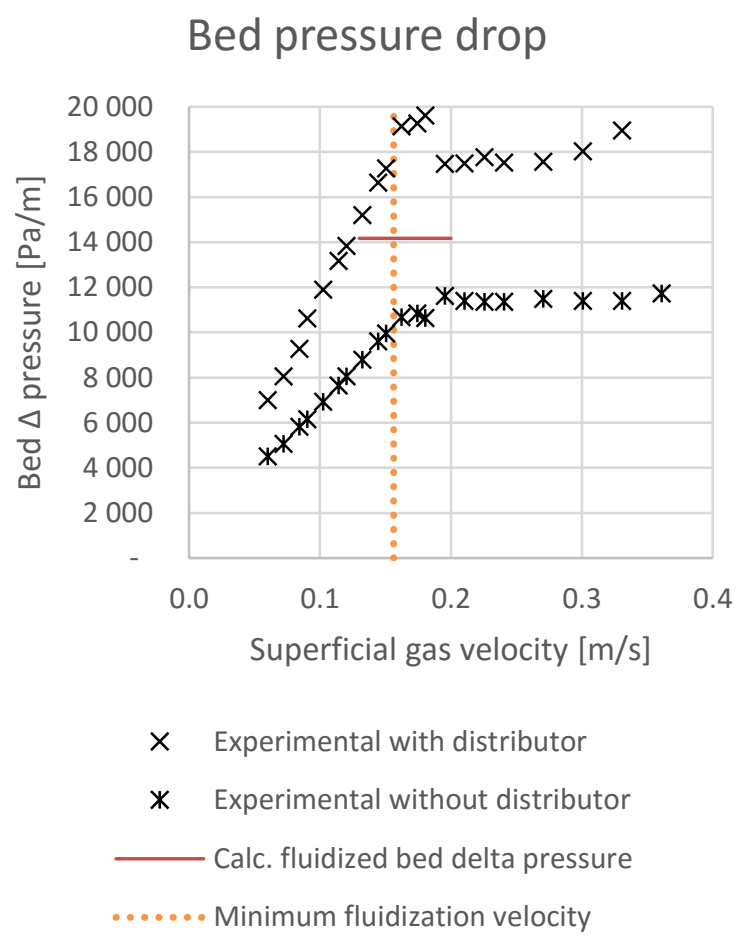

Figure 3. Experimental bed pressure drop. The red line shows static pressure calculated from weight of bed material.

\subsection{CFD Simulation Results}

Initial simulations were performed using the sphericity corrected nominal diameter, that is for $a=1$ in Equation (4). Results from simulations are shown in Figure 4 through Figure 6 for the different drag models. The simulated minimum fluidization velocity based on Syamlal \& O'Brien drag model agrees very well with the experimental result as expected since the model parameters have been fitted. Moreover, the agreement between the simulated result and the experimental data is better using the BVK drag model compared with the Gidaspow drag model. For the bed height increase, there is a significant variation in the results obtained from the different drag models. 
It should be noted that for further comparison of the drag models, each drag model is modified by incorporating the effect of sphericity in the nominal particle diameter as described in Equation (4). The value of the parameter $a$ for each drag model is obtained by trial based on the simulated minimum fluidization velocity compared with the experimental data. Linear interpolation is also employed to reduce the number of trial simulations. The results are summarized in Table 5 and Figure 7. When the optimum particle diameter are used, all the drag models give the same minimum fluidization velocity as the experiment.

\section{Syamlal \& O'Brien drag model}

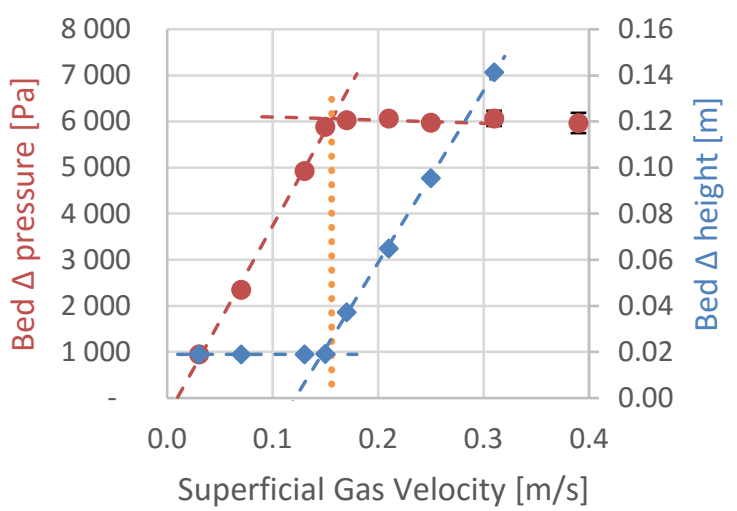

Figure 4. Bed pressure drop (red-left) and bed height increase (blue-right) from simulation using Syamlal \& O'Brien drag model, particle diameter $363 \mu \mathrm{m}$. Error bars indicate variation due to bubbles. Dotted line marks the experimental minimum fluidization velocity.

\section{Gidaspow drag model}

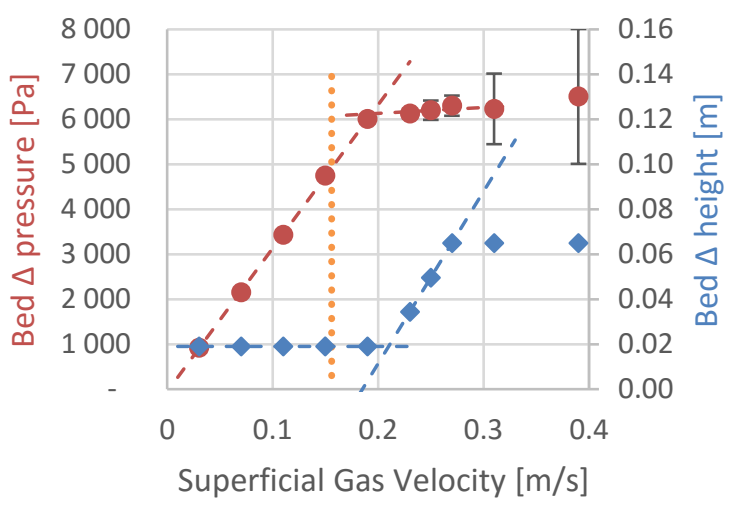

Figure 5. Bed pressure drop (red-left) and bed height increase (blue-right) from simulation using Gidaspow drag model, particle diameter $363 \mu \mathrm{m}$. Error bars indicate variation due to bubbles. Dotted line marks the experimental minimum fluidization velocity.

\section{BVK drag model}

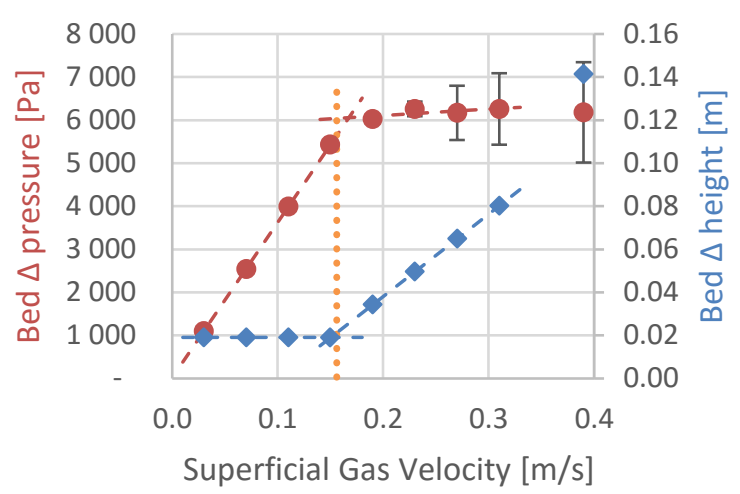

Figure 6. Bed pressure drop (red-left) and bed height increase (blue-right) from simulation using BVK drag model, particle diameter $363 \mu \mathrm{m}$. Error bars indicate variation due to bubbles. Dotted line marks the experimental minimum fluidization velocity.

Table 5. Minimum fluidization velocity from simulations using various particle diameters and drag models. The experimentally determined minimum fluidization velocity is $0.156 \mathrm{~m} / \mathrm{s}$. The value $a$ refers to Equation (4).

\begin{tabular}{|c|c|c|c|}
\hline $\begin{array}{c}\text { Particle } \\
\text { diameter }\end{array}$ & $\begin{array}{c}\text { Syamlal \& } \\
\text { O'Brien } \\
\text { (fitted) }\end{array}$ & Gidaspow & $B V K$ \\
\hline $242 \mu \mathrm{m}$ & & $0.076 \mathrm{~m} / \mathrm{s}$ & $0.075 \mathrm{~m} / \mathrm{s}$ \\
\hline $363 \mu \mathrm{m}$ & $0.156 \mathrm{~m} / \mathrm{s}$ & $0.200 \mathrm{~m} / \mathrm{s}$ & $0.167 \mathrm{~m} / \mathrm{s}$ \\
\hline $484 \mu \mathrm{m}$ & $0.153 \mathrm{~m} / \mathrm{s}$ & $0.330 \mathrm{~m} / \mathrm{s}$ & $0.350 \mathrm{~m} / \mathrm{s}$ \\
\hline \multicolumn{2}{|c|}{ Optimum diameter } & $\begin{array}{c}319 \mu \mathrm{m} \\
a=1.45\end{array}$ & $\begin{array}{c}358 \mu \mathrm{m} \\
a=1.05\end{array}$ \\
\hline
\end{tabular}

\subsection{Bed behavior}

The simulated bed heights at different gas velocities are compared for different drag models as shown in Figure 8. The optimum equivalent diameters from Table 5 are used for these simulations. The two different particle diameters using Syamlal \& O'Brien drag model show identical bed behavior: Steady increase in the bed height and particulate fluidization above minimum fluidization velocity. No evidence of bubble flow using this model.

Using the Gidaspow and BVK drag models, the bed shows a similar behavior. There is a strong evidence of a well-defined bubble formation and less defined bed height. The bed height obtained from these models are smaller than those from the Syamlal \& O'Brien drag model for the same gas velocity above the minimum fluidization velocity. However, the results from the BVK model are slightly lower when compared with those from the Gidaspow model. The two sets of simulations using BVK drag model with two close 
particle diameters do not overlap, indicating strong sensitivity of this model with particle diameter.

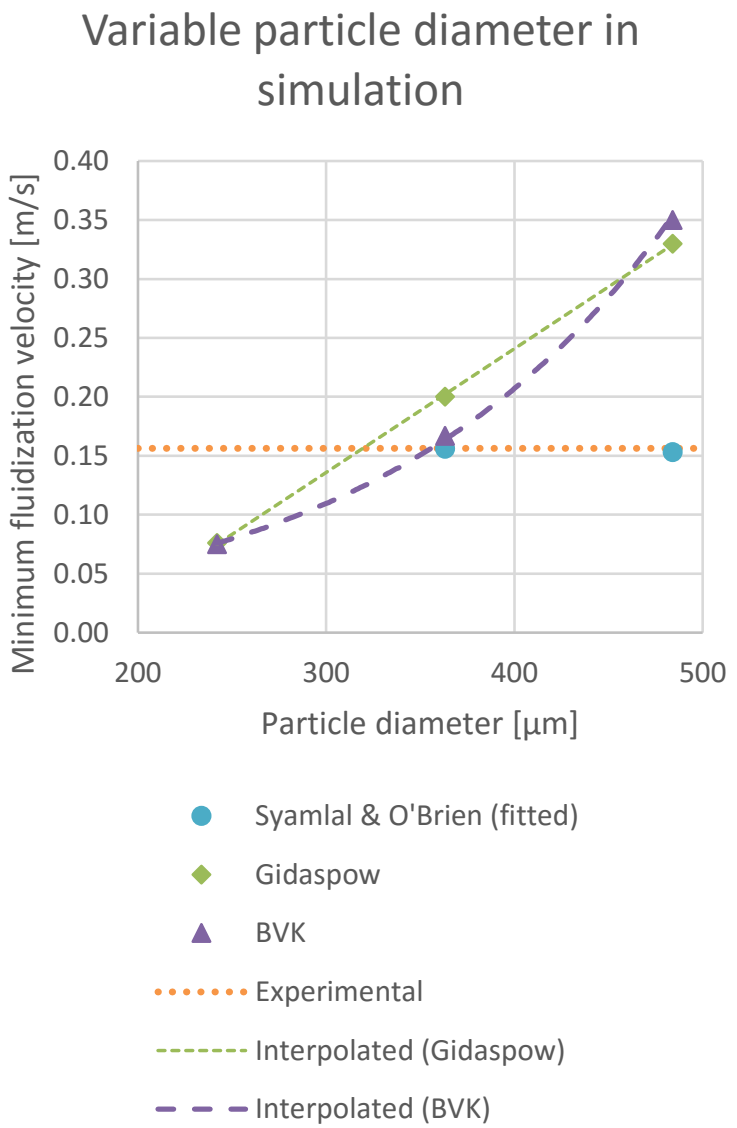

Figure 7. Minimum fluidization velocity from simulations using particle diameters 242,363 and $484 \mu \mathrm{m}$.

Figure 9 shows the simulated pressure drops using different drag models as compared with the experimental data. As the superficial gas velocity is increased, the bed pressure drop per unit length increases up to the minimum fluidization velocity. As can be seen, the simulation results lie between the two sets of experimental data. The experimental data show a substantial effect of using a distributor plate. The lower pressure drop without distributor plate might be explained from the channeling effects where only a part of the bed is lifted upon fluidization. The red line in Figure 9 corresponds to the calculated static pressure from lifting the weight of the bed, which is independent on bed height though. Theoretically, this corresponds to the bed pressure drop at the point of minimum fluidization velocity.

\section{Height of bed from simulation}

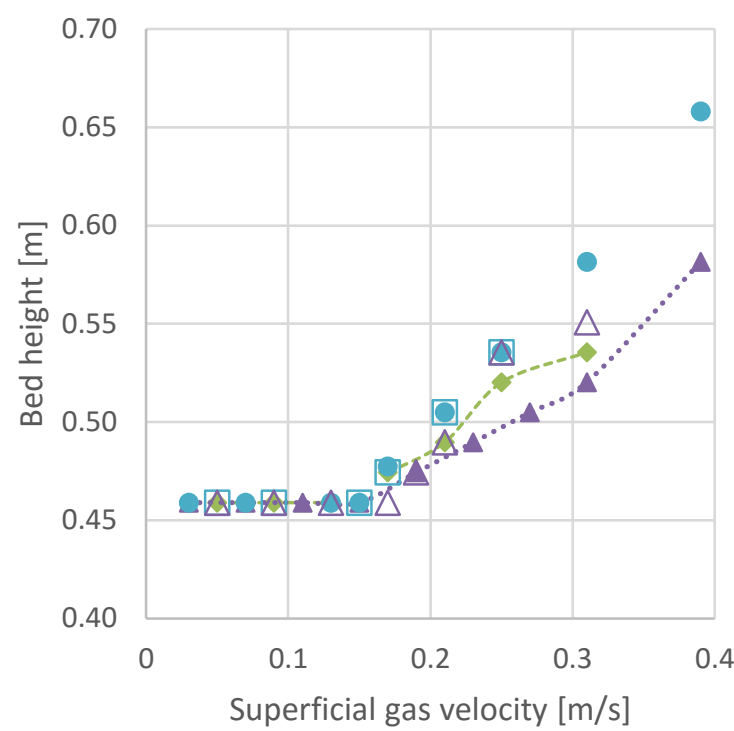

- Syamlal \& O'Brien $363 \mu \mathrm{m}$

$\square \quad$ Syamlal \& O'Brien $484 \mu \mathrm{m}$

-- $\rightarrow---$ Gidaspow $319 \mu \mathrm{m}$

........ BVK $363 \mu \mathrm{m}$

$\triangle \quad$ BVK $358 \mu \mathrm{m}$

Figure 8. Height of bed from simulation.

Slightly above the point of minimum fluidization velocity, the bed pressure drop decreases and then remains constant. This effect is also accompanied with a slight bed expansion to allow passage of bubbles. As the bed remains in bubbling regime, the bed pressure drop remains constant. This behavior is also captured with the simulation results.

In (Agu et al., 2017), the solids fraction distribution was measured at different gas velocities in a set up equipped with a dual-plane Electrical Capacitance Tomography (ECT) sensors with the $484 \mu \mathrm{m}$ sand particles as the bed material. Figure 10 and Figure 11 show the ECT images of the solid fraction in the bed, which are stacked in time for $10 \mathrm{~s}$ of the airflow at 0.25 and $0.31 \mathrm{~m} / \mathrm{s}$, respectively. The number of bubbles passing through the bed per unit time can easily be seen. The bubbles coalesce into single larger bubbles as they rise up the bed. 


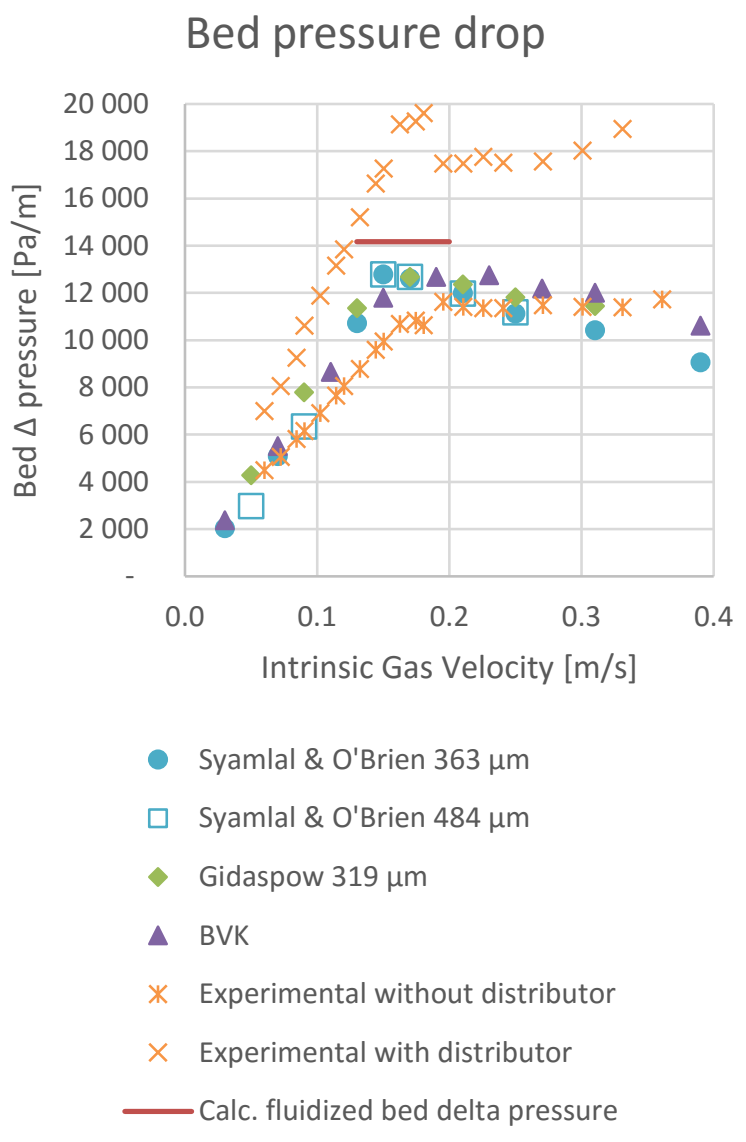

Figure 9. Bed pressure drop per unit bed length, experimental and simulated.

Variations of simulated pressure at the bottom of the bed against the time are shown in Figure 12 through Figure 17. The variations of void fraction at the same position in the bed are also shown for comparison.

Table 6 compares the computed bubble frequencies based on the simulation using the Gidaspow and BVK drag models and with those obtained from the experimental results shown in Figure 10 and Figure 11. For the Syamlal \& O'Brien drag model, no bubble flow is predicted. As can be seen, the bubble frequencies from the Gidaspow and BVK are fairly in agreement with the experimental data.

Table 6. Frequency of bubbles escaping the bed.

\begin{tabular}{|l|c|c|c|}
\hline $\begin{array}{l}\text { Superficial } \\
\text { gas } \\
\text { velocity }\end{array}$ & $\begin{array}{l}\text { Gidaspow } \\
\text { drag } \\
\text { model }\end{array}$ & $\begin{array}{l}\text { BVK drag } \\
\text { model }\end{array}$ & $\begin{array}{l}\text { Experimental } \\
(28.7 \text { cm from } \\
\text { bottom) }\end{array}$ \\
\hline $0.19 \mathrm{~m} / \mathrm{s}$ & $5-6 \mathrm{~s}^{-1}$ & $5-6 \mathrm{~s}^{-1}$ & \\
\hline $0.23-$ & $2.2-$ & $2.2-$ & \\
$0.31 \mathrm{~m} / \mathrm{s}$ & $2.6 \mathrm{~s}^{-1}$ & $2.6 \mathrm{~s}^{-1}$ & \\
\hline $0.25 \mathrm{~m} / \mathrm{s}$ & & & $1.5 \mathrm{~s}^{-1}$ \\
\hline $0.31 \mathrm{~m} / \mathrm{s}$ & & & $1.1 \mathrm{~s}^{-1}$ \\
\hline
\end{tabular}

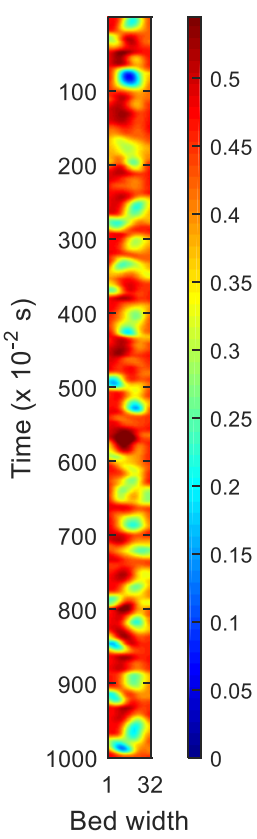

(a)

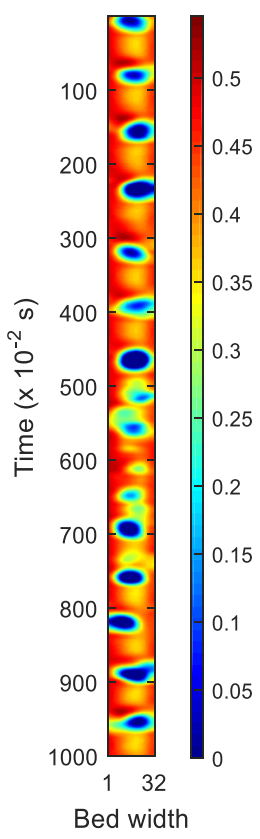

(b)
Figure 10. ECT images for $10 \mathrm{~s}$ of the flow in bed of $483 \mu \mathrm{m}$ sand particles at $25 \mathrm{~cm} / \mathrm{s}$ : (a) lower plane: $15.7 \mathrm{~cm}$ from the bottom (b) upper plane: $28.7 \mathrm{~cm}$ from bottom. Time axis increases from top to bottom.

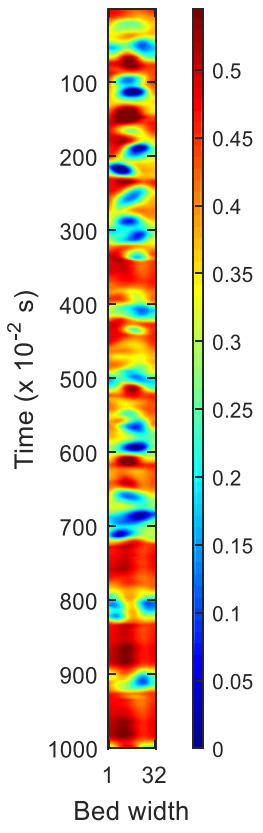

(a)

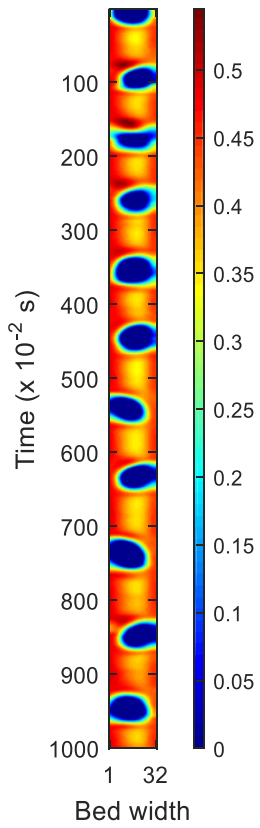

(b)
Figure 11. ECT images for $10 \mathrm{~s}$ of the flow in bed of $483 \mu \mathrm{m}$ sand particles at $31 \mathrm{~cm} / \mathrm{s}$ : (a) lower plane: $15.7 \mathrm{~cm}$ from the bottom (b) upper plane: $28.7 \mathrm{~cm}$ from bottom. Time axis increases from top to bottom. 


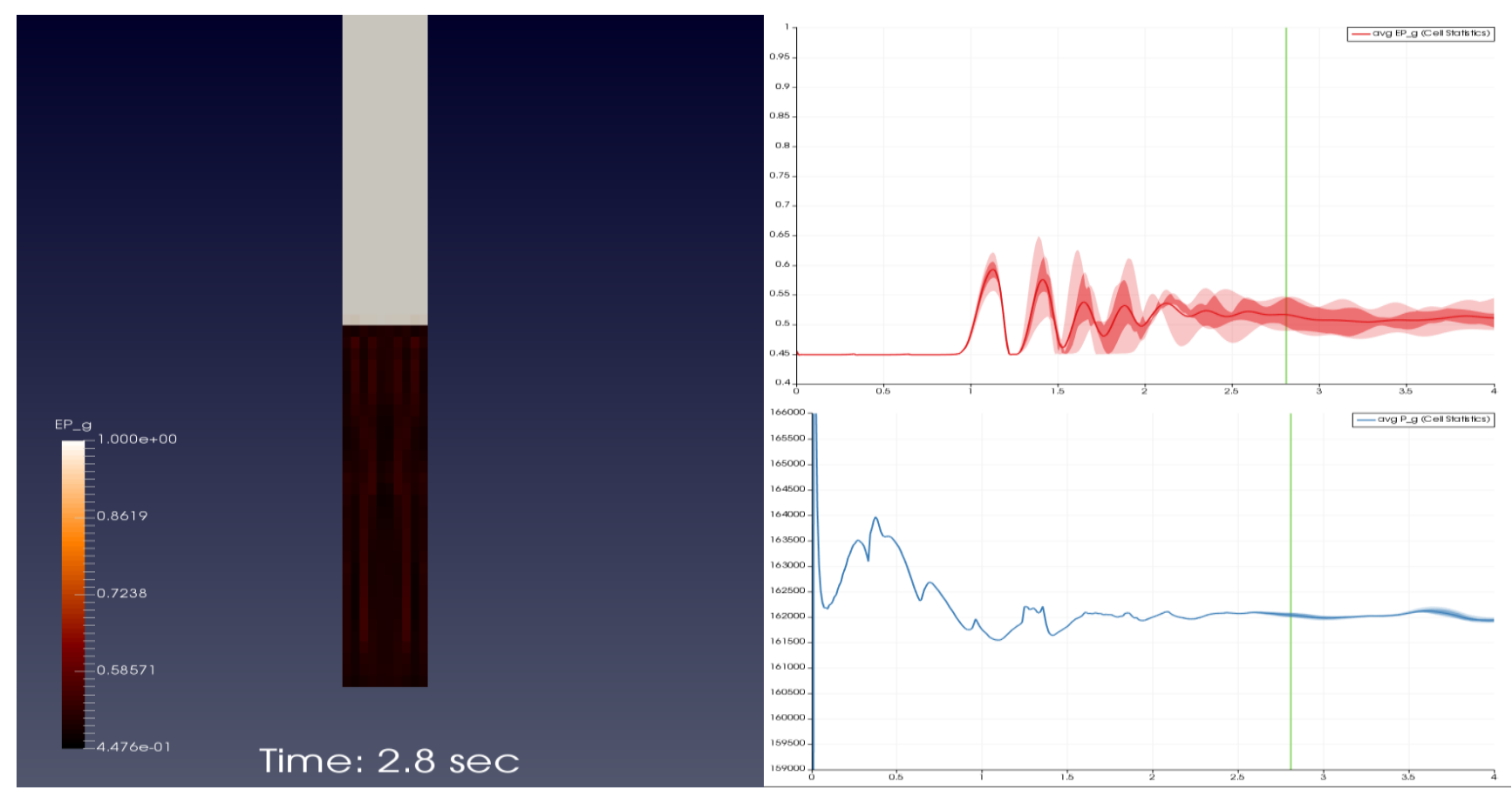

Figure 12. Syamlal \& O'Brien drag model simulation for $0.21 \mathrm{~m} / \mathrm{s}$ intrinsic gas velocity (363 $\mu \mathrm{m}$ particles). Top right shows time profile for void fraction at initial top of bed (scale 0.4 to 1.0). Bottom right shows time profile for pressure at bottom of bed (scale $\Delta$ pressure range $700 \mathrm{~Pa}$ ).

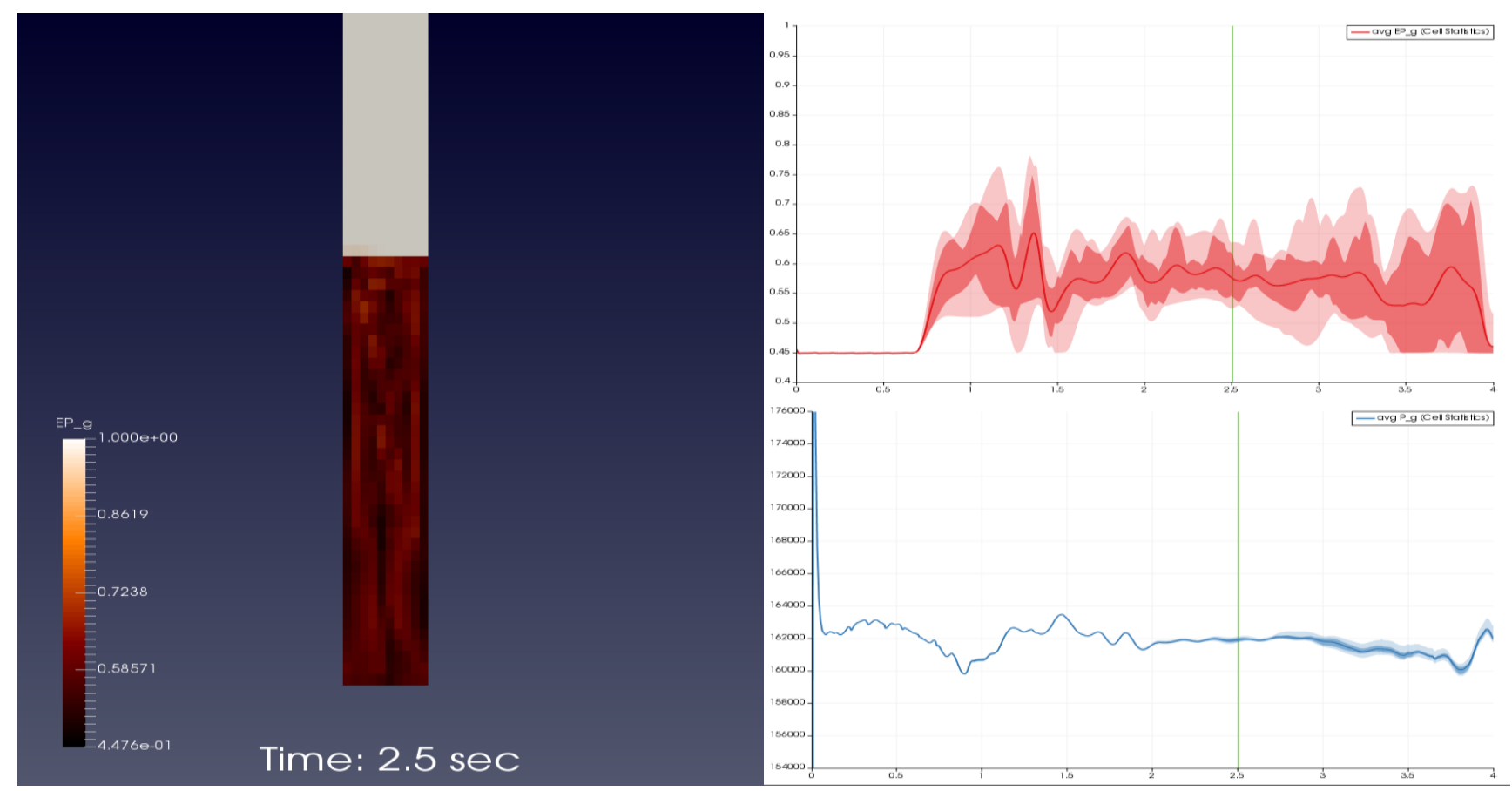

Figure 13. Syamlal \& O’Brien drag model simulation for $0.31 \mathrm{~m} / \mathrm{s}$ intrinsic gas velocity (363 $\mu \mathrm{m}$ particles). Top right shows time profile for void fraction at top of bed (scale 0.4 to 1.0). Bottom right shows time profile for pressure at bottom of bed (scale $\Delta$ pressure range $2200 \mathrm{~Pa}$ ). More channeling evolved at later simulation times. 

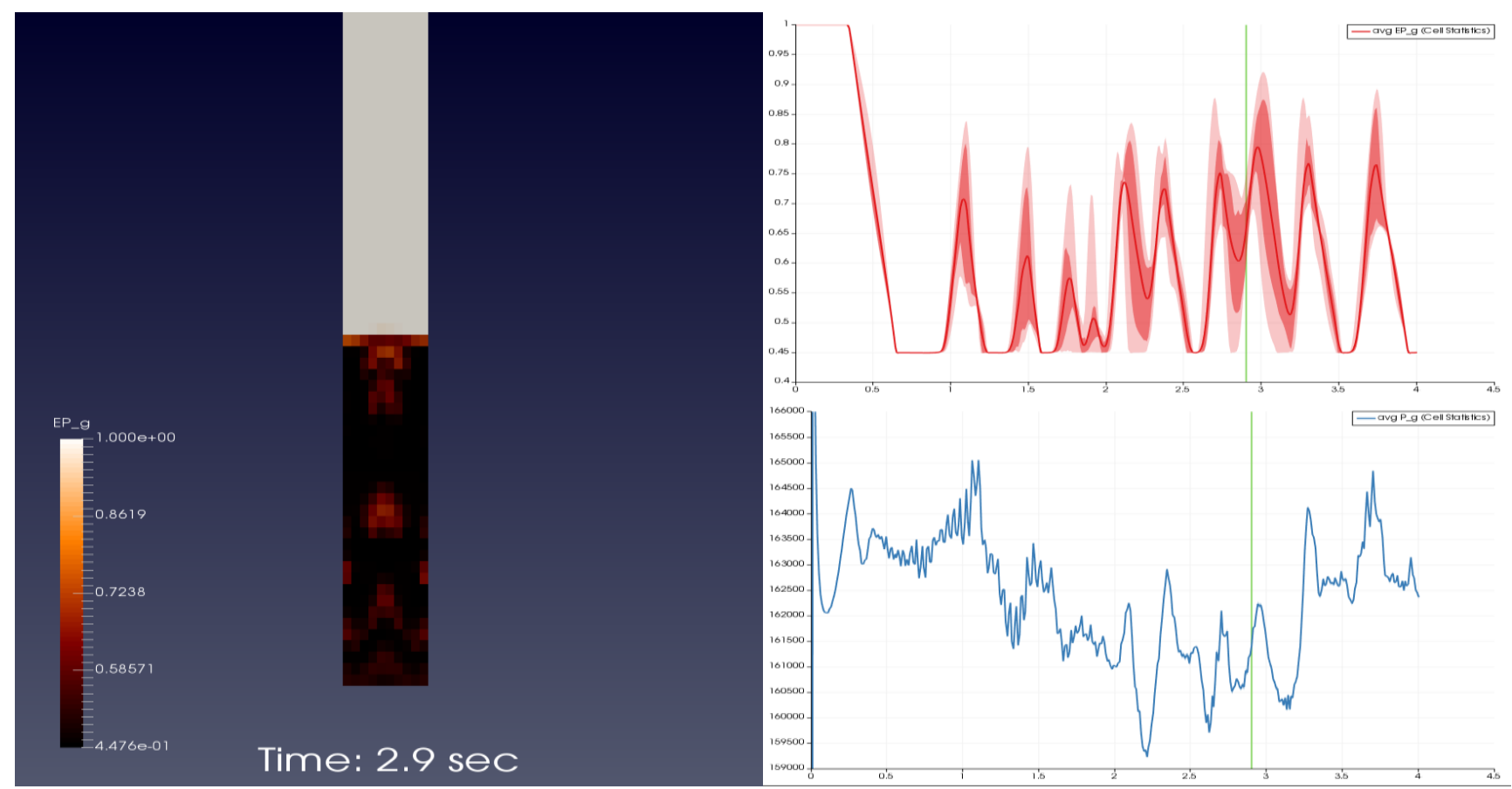

Figure 14. Gidaspow drag model simulation for $0.21 \mathrm{~m} / \mathrm{s}$ intrinsic gas velocity $(319 \mu \mathrm{m}$ particles $)$. Top right shows time profile for void fraction at top of bed. Bottom right shows time profile for pressure at bottom of bed (scale $\Delta$ pressure range $700 \mathrm{~Pa}$ ).

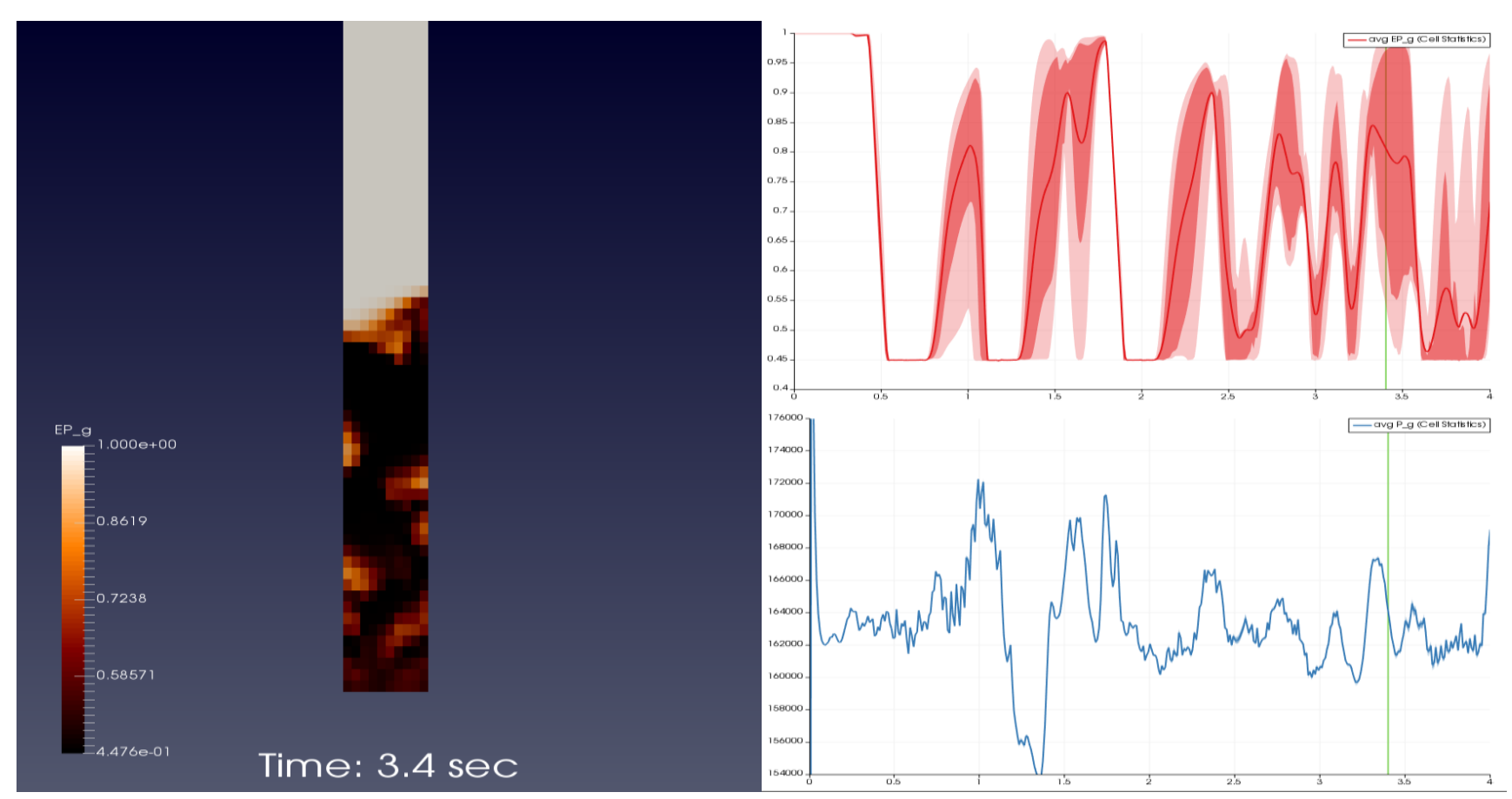

Figure 15. Gidaspow drag model simulation for $0.31 \mathrm{~m} / \mathrm{s}$ intrinsic gas velocity $(319 \mu \mathrm{m}$ particles). Top right shows time profile for void fraction at top of bed (scale 0.4 to 1.0). Bottom right shows time profile for pressure at bottom of bed (scale $\Delta$ pressure range $2200 \mathrm{~Pa}$ ). 


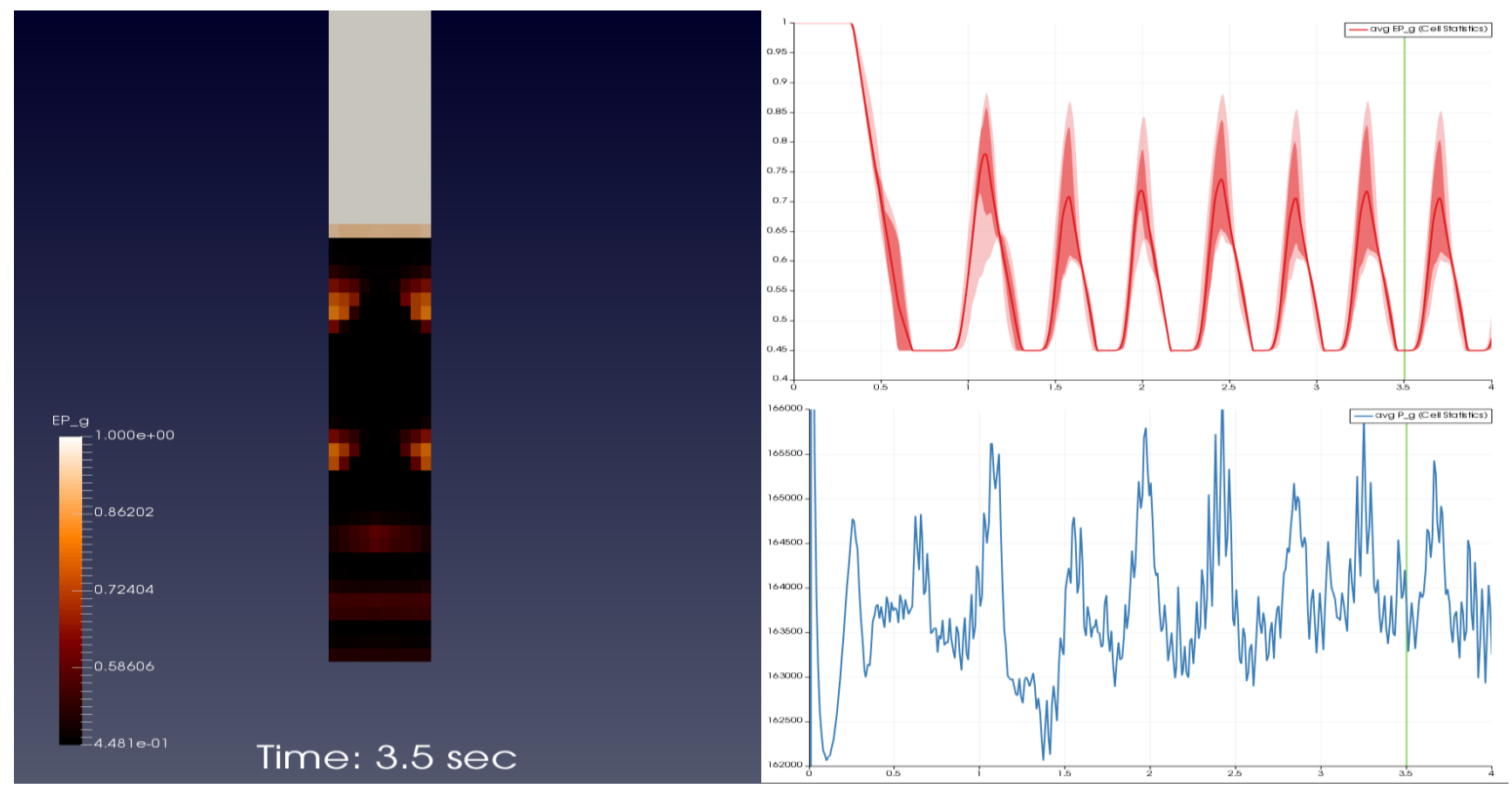

Figure 16. BVK drag model simulation for $0.23 \mathrm{~m} / \mathrm{s}$ intrinsic gas velocity. Top right shows time profile for void fraction at top of bed (scale 0.4 to 1.0). Bottom right shows time profile for pressure at bottom of bed (scale $\Delta$ pressure range $400 \mathrm{~Pa}$ ).

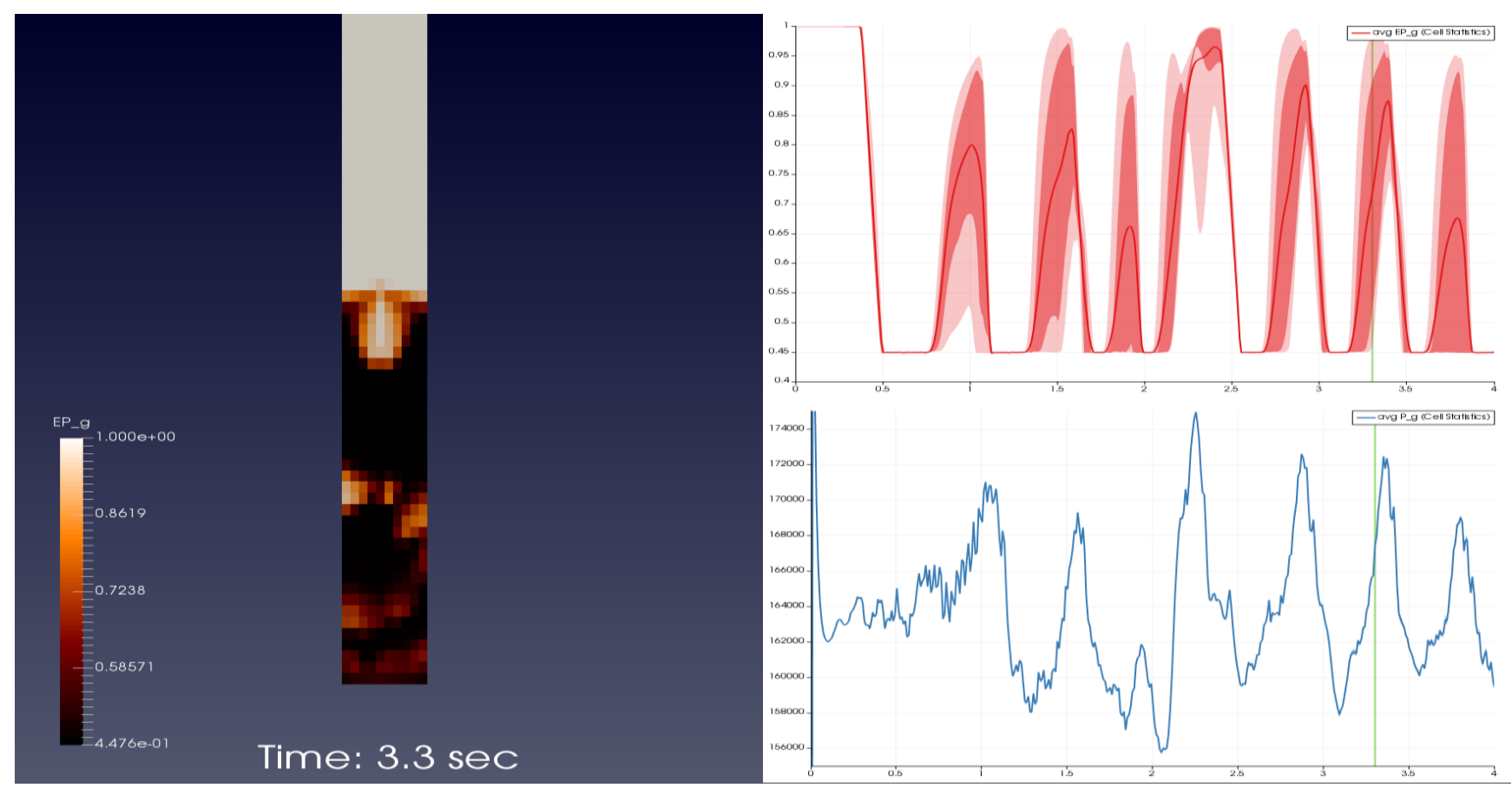

Figure 17. BVK drag model simulation for $0.31 \mathrm{~m} / \mathrm{s}$ intrinsic gas velocity. Top right shows time profile for void fraction at top of bed (scale 0.4 to 1.0 ). Bottom right shows time profile for pressure at bottom of bed (scale $\Delta$ pressure range $2000 \mathrm{~Pa}$ ). 


\section{Conclusions}

The Syamlal \& O'Brien drag model parameters are fitted versus the experimental minimum fluidization velocity and thereby reproduce this bed behavior independent from choice of particle diameter used in simulation. This allows for the number of particles in simulation being close to the actual number of particles used experimentally. The bubbling bed behavior was not captured.

The BVK drag model reproduced the experimental minimum fluidization velocity when sphericity corrected diameter of particles were used. On the other hand, simulations using alternative particle diameters showed rather high sensitivity to simulation particle diameter, and verification versus experimental data is recommended.

The Gidaspow drag model resulted in a rather large deviation from experimental results when the sphericity corrected diameter was used. On the other hand, optimizing the simulation particle diameter resulted in bed behavior close to using the BVK drag model. Both models resulted in similar bed height increase and bubble size and frequency. There was a significant deviation from experimental results on bed height increase (unit length pressure drop) and bubble frequency for both models.

\section{References}

Agu C. E., Tokheim L.-A. and Halvorsen B. M. (2017, May). Measurement Of Bubble Properties In A Fluidized Bed Using Electrical Capacitance Tomography. Paper presented at the 12th International Conference on Circulating Fluidized Bed CFB-12, Krakow, Poland.

Beetstra R., van der Hoef M. A. and Kuipers J. A. M. (2007). Numerical study of segregation using a new drag force correlation for polydisperse systems derived from latticeBoltzmann simulations. Chemical Engineering Science, 62(1-2), 246-255 doi:http://dx.doi.org/10.1016/j.ces.2006.08.054

Ding J. and Gidaspow D. (1990). A bubbling fluidization model using kinetic theory of granular flow. AIChE Journal, 36(4), 523-538. doi:10.1002/aic.690360404

Krumbein W. C. (1941). Measurement and Geological Significance of Shape and Roundness of Sedimentary Particles. Journal of Sedimentary Petrology, 11(2), 64-72.

Li T., Grace J. and Bi X. (2010). Study of wall boundary condition in numerical simulations of bubbling fluidized beds. Powder Technology, 203(3), 447-457. doi:http://dx.doi.org/10.1016/j.powtec.2010.06.005

Syamlal M. Determining Drag Coefficients to Match Umf [Excel calculation sheet]: Fluent, Inc. Retrieved from https://mfix.netl.doe.gov/mfix/mfix-documentation/

Syamlal M. and O'Brien T. J. (1988). Simulation of granular layer inversion in liquid fluidized beds. International Journal of Multiphase Flow, 14(4), 473-481. doi:http://dx.doi.org/10.1016/0301-9322(88)90023-7
Syamlal M., Rogers W. and O`Brien T. J. (1993). MFIX documentation theory guide. Retrieved from http://www.osti.gov/scitech/servlets/purl/10145548

Wadell H. (1935). Volume, Shape, and Roundness of Quartz Particles. The Journal of Geology, 43(3), 250-280. doi: $10.1086 / 624298$ 